\section{ФИЛОСОФИЯ}

представлен в наших умозрительных построениях. В сознании возникает мысленная конструкция исторического события, освоенная нами в форме образа, содержание которого спроецировано на раздражитель, его вызвавший, - определенное историческое событие. Это значит, что, осваивая историю, мы имеем дело не с явлением, принадлежащим к настоящему или в интерпретации Н. Гартмана наличному бытию, а с его информационной проекцией, ставшей посредником между действительностью и перципиентом, непосредственно влияющей на содержательную сторону картины социально-исторической реальности. Образ исторического события создается на границе соединения сообщений, поступающих из внешней среды и внутреннего информационного архива личности, на этом уровне ему придается определенный смысл и значение. Следовательно, мы имеем дело не с самой реальностью, а с ее мифологемой.

Появление мифологемы картины социальной истории - результат практики освоения исторического процесса в целях приведения сведения об истории в определенную систему, отражающую сущность и движущие силы эволюции общества. Мифологема, возникающая вследствие синтеза известного и предполагаемого, становится одним из атрибутов исторического знания, функция которого заключается в объединении образов прошлого с культурной парадигмой настоящего. Мифологема, в самом общем виде, представляет собой форму организации картины социально-исторической реальности, обеспечивающую органическую адаптацию исторической информации к потребностям общественного субъекта в контексте императивов культуры рационального познания. Мифологема социально-исторической реальности - это результат отражения исторического в сознании субъекта, конкретного выражения настоящего, носителя определенного способа освоения исторического.

УДК 165.6+81-116

Науч. спец. 09.00 .01

DOI: 10.36809/2309-9380-2020-28-52-55

\section{ПРОСТРАНСТВЕННОЕ МЫШЛЕНИЕ В ФИЛОСОФИИ ЯЗЫКА: ОТ СТРУКТУРНОЙ ЛИНГВИСТИКИ К ПОСТСТРУКТУРАЛИЗМУ}

В статье проанализированы пространственные представления о природе человеческого языка, характерные для лингвистики и философии XX в. На примере творчества лингвиста Л. Ельмслева, философов Ж. Делёза и У. Эко показано, что пространственный способ мышления не только об объектах действительности, но и об объектах символического универсума культуры, важнейшие элементы которого - языки - необходимый способ формирования философских представлений о существующих смыслах и способах их выражения.

Ключевые слова: философия языка, структурная лингвистика, философские концепты, эпистемологический конструктивизм.
1. Гартман Н. Познание в свете онтологии // Западная философия. Итоги тысячелетия. Екатеринбург : [б. и.], 1997. 654 с.

2. Гартман Н. К основоположению онтологии. СПб. : Наука, 2003. 640 с.

3. Сыров В. Н. Введение в философрию истории: Своеобразие исторической мысли. М. : Водолей Publishers, 2006. 246 с.

4. Солодухо Н. М. Философия небытия. Казань : Изд-во Казан. гос. техн. ун-та, 2002. 146 с.

5. Гречко П. К. Концептуальные модели истории // Библиотека Гумер - история : [сайт]. URL: /http://www. gumer. info/bibliotek_Buks/History/Grech/index.php. (дата обращения: 14.05.2020).

6. Энгельс Ф. Анти-Дюринг // Маркс К., Энгельс Ф. Сочинения : в 39 т. М. : Госполитиздат, 1961. Т. 20. С. 5-342.

7. Перов Ю. В. Историчность и историческая реальность. СПб. : Санкт-Петербургское философское общество, 2000. $144 \mathrm{c}$.

8. Мегилл А. Историческая эпистемология : моногр. М. : Канон+, РООИ «Реабилитация», 2007. 480 с.

9. Николаева Е. М. Социализация личности: синергетический дискурс (опыт социально-философрского исследования). Казань : Изд-во Казан. ун-та, 2005. 176 с.

10. Степанов А. Г. Факторы социальной детерминации системы социально-исторического познания // Вестн. Чуваш. ун-та. 2011. № 1. С. 154-160.

11. Алексеенко Н. Ю. Предисловие // Восприятие. Механизмы и модели / под ред. Н. Ю. Алексеенко. М. : Мир, 1974. C. 9-15.

12. Дильтей В. Собрание сочинений : в 6 т. М. : Три квадрата, 2004. Т. 3. 331 c.

(C) Степанов А. Г., 2020

\title{
SPATIAL THINKING IN THE PHILOSOPHY OF LANGUAGE: FROM STRUCTURAL LINGUISTICS TO POSTSTRUCTURALISM
}

The article analyses the spatial concepts of the nature of the human language, characteristic of linguistics and philosophy of the $20^{\text {th }}$ century. On the example of the creativity of the linguist L.T. Hjelmslev, the philosophers G. Deleuze and U. Eco, it is shown that the spatial way of thinking not only about objects of reality, but also about objects of the symbolic universe of culture, the most important element of which is languages, is a necessary way of forming philosophical ideas about existing meanings and ways of expressing them.

Keywords: philosophy of language, structural linguistics, philosophical concepts, epistemological constructivism. 
Рассуждая о способах познания мира, И. Кант писал, что люди способны созерцать вещи лишь через посредство формы чувственного созерцания, а свойственные человеку формы чувственности - пространство и время - предшествуют всякому эмпирическому созерцанию. «Посредством внешнего чувства (свойства нашей души) мы представляем себе предметы как находящиеся вне нас и притом всегда в пространстве» [1; 2, с. 51]. Следуя этой фрилософрской традиции рассуждения о человеческом мире пространства и времени, Э. Кассирер полагал, что вне условий пространства и времени человек не может познать ни один реальный предмет, поскольку это структуры, в которые вмещается вся реальность. Одна из самых важных задач антропологической философии, по мнению Э. Кассирера, - «описывать и анализировать специфические черты, которые приобретают пространство и время в человеческом опыте...» [3, с. 490]. Философ уверен, что поскольку человек формируется и проживает свою жизнь в среде культуры, которая представляет собой сферу символического, философия должна анализировать пространство символического, что позволило бы «проникнуть в самую суть и общую направленность культурной жизни человечества» [3, с. 493].

Пространственное представление о вещах материальных, протяженных - необходимое следствие взаимодействия человека с материальным миром, однако категория пространства оказалась незаменимой и для мышления о такой, казалось бы, нематериальной символической сущности, как человеческий язык. Лингвисты могут возразить, что язык актуализируется и материализуется в звуках речи и письменных текстах, однако равнозначно важная часть языка - значения слов и смыслы текстов - не имеет физической природы и существует лишь благодаря мыслительной деятельности людей. Если Аристотель определял язык как звук со смыслом, то к началу XXI в. всё больше философров и лингвистов стали склоняться к тому, что язык - это смысл со звуком. Для философии XX в. было характерно повышенное внимание к сущности естественного языка и других знаковых систем, при этом в своих размышлениях философы нередко опирались на идеи, высказанные лингвистами. Так, мы можем проследить влияние идей структурной лингвистики, активно развивавшейся в первой половине XX в., на творчество таких философов второй половины XX в., как Ж. Делёз и У. Эко. Вместе с тем можно заметить, как сам язык влияет на характер рассуждений философов, поскольку конкретный язык определяет способ видения мира, даже если философ рассуждает о чем-то абстрактном.

Обратимся сначала к идеям лидера датской школы структурной лингвистики (или глоссематики) Луи Ельмслева, который вместе с единомышленниками предпринял попытку создать строгую теорию языка, сравнимую с естественно-научными теориями. По мнению датских структуралистов, лингвистическая теория должна стараться отделить внутреннюю структуру языка от внешнего контекста, она разграничивает язык как систему и текст/речь как ее актуализацию. Основная заслуга Ельмслева, как ее определили впоследствии Ж. Делёз и У. Эко, состоит в выделении во всяком естественном языке двух взаимно соотнесенных планов: плана выражения и плана содержания. План выражения - это все языковые средства, план содержания — весь комплекс понятий и смыслов, которые могут быть выражены. При этом создатель глоссематической теории подчеркивал, что план содержания и план выражения определяются лишь путем оппозиции и соотнесения как противоположенных друг другу функтив одной функции, и различие между содержанием и выражением - основа структуры любого языка. «Определенное выражение есть выражение постольку, поскольку это выражение содержания, а содержание является содержанием постольку, поскольку это содержание выражения» [4, с. 70]. Согласно этой теории, «...благодаря форме содержания и форме выражения и только благодаря им, существуют соответственно субстанция содержания и субстанция выражения» [4, с. 80]. При анализе любого текста как линейного процесса можно выделить линию выражения и линию содержания. При анализе языковой системы можно установить две ее парадигмы: сторону выражения и сторону содержания. Выбор термина «план содержания» для общего названия линии содержания и стороны содержания, как и термина «план выражения» для общего названия линии выражения и стороны выражения, Ельмслев объясняет, ссылаясь на формулировку вдохновившего его швейцарского лингвиста Ф. де Соссюра, который говорил о «бесконечном плане смутных идей» и «столь же неопределенном плане звуков», которые существуют до того, как язык осуществит свою работу по вычленению оформленных субстанций смысла и звучащих высказываний [4, с. 73]. В «Пролегоменах» Л. Ельмслев использует только термины «сторона» и «план», однако в дальнейшем в трудах школы структурной лингвистики вводится членение языка на четыре «пласта» или «слоя» (strata), исходя из двух дихотомий: содержание vs выражение и субстанция vs форма [5, c. 202]. Чтобы осмыслить дальнейшие метаморфозы термина «план» в рассуждениях философов о языке, следует учесть, что возможными значениями слова «план» (plané) во французском языке, на котором изначально были записаны тексты Ф. де Соссюра, являются «плоскость» и «уровень».

Идея пласта, слоя или плоскости применительно к звучащему языку и области смыслов получила дальнейшее развитие в творчестве французских философов Ж. Делёза и Ф. Гваттари, которые высоко ценили идею Л. Ельмслева о существовании в языке независимых друг от друга плана содержания и плана выражения. По их мнению, предложенная датским структуралистом сеть понятий не является чисто лингвистической по своим масштабам и сфере применения, поэтому в совместном труде «Тысяча плато» философы обыгрывают идею слоя, или пласта, — stratum применительно к материальному миру, распространяя ее на протекающие в нем геологические и биологические процессы, описывая принципы сложного взаимодействия неорганических и органических пластов с бесформенной материей в плане консистенции, который поставляет материал для их формирования [6, р. 45]. В дополнение к геологическому и биологическому пластам философы выделяют третий слой, сформировавшийся над ними в ходе эволюции человека и развития человеческого общества, - слой языка (фактически разнообразных человеческих языков). Делёз и Гваттари подробно разбирают свойства этого 
пласта, включающего в себя смыслы и знаки, т. е. мыслимое содержание и звуковое выражение. Философы полагают, что все пласты-strata являются сгущениями в плане консистенции, который первичен и вездесущ. Формы и субстанции могут существовать только внутри пластов, тогда как план консистенции, или планоменон, представляет собой неупорядоченный и непрерывно изменчивый хаокосмос. В дальнейшем идею формирования пластов в пространстве хаокосмоса Делёз и Гваттари трансформируют в работе «Что такое философия?», где излагают свое понимание процесса создания философских концептов как одной из важнейших задач философов и способом философркого осмысления мира. «...Каждый концепт должен... рассматриваться как точка совпадения, сгущения и скопления своих составляющих ...концепт есть не что иное, как мыслительный акт...» [7, с. 31]. Философрия - это конструирование, которое включает в себя «...два взаимодополнительных и разноприродных аспекта - создание концептов и начертание плана. <... > Концепты суть события, а план - горизонт событий, резервуар или же резерв чисто концептуальных событий...» [7, с. 48-49]. С одной стороны, план имманенции - это образ мысли, но, с другой стороны, - это некая секущая плоскость, проходящая сквозь космический хаос, это «...как бы срез хаоса, и действует он наподобие решета»; осуществляя сечение хаоса, план имманенции призывает к созданию концептов [7, с. 57-58]. Описывая пространственное видение плана имманенции и концептов, Делёз и Гваттари сравнивают план имманенции со столом, подносом или чашей, на которой или внутри которой находятся философские концепты - «...фрагментарные единства, не пригнанные друг к другу, так как их края не сходятся»; «концепты напоминают архипелаг островов... тогда как план подобен дыханию, овевающему эти изолированные островки»; «концепты - это абсолютные поверхности или объемы, неправильные по форме и фрагментарные по структуре, тогда как план представляет собой абсолютную беспредельность и бесформенность, которая не есть ни поверхность, ни объем, но всегда фрактальна» [7, с. 49-50]. Фактически для рассуждения о такой нематериальной области универсума, как мир идей или смыслов, философрам необходимо пространственное мышление и представление о форме и объеме.

Н. И. Мартишина в своем анализе идей Ж. Делёза и Ф. Гваттари, изложенных в сочинении «Что такое философия?» отмечает, что «в развертывании познания может происходить конструирование реальности в форме ее достройки или конструирование самостоятельной реальности», благодаря чему в познавательном отражении мира возникают идеальные объекты специфического типа, которые в философской литературе обозначаются как «конструкты» [8, с. 136]. В связи с творчеством фрранцузских философов уместно говорить об эпистемическом конструктивизме, который рассматривает именно конструирование идей различного вида. Философское абстрагирование может порождать «...концепты, которым не соответствуют в объективной реальности ни конкретные, ни даже отдаленные аналоги: они изначально вводятся как внутрикогнитивные феномены, выступающие как средства построения теории» [8, с. 137]. Исследователь приходит к за- ключению, что «осознание конструирования реальностей как процесса, всё время совершающегося и в философрствовании, и в культурной деятельности вообще, является отправной точкой философии постмодернизма» [8, с. 156].

У. Эко, посвятивший множество работ исследованию природы языка и других знаковых систем, опираясь на идеи глоссематики, размышляет о плане содержания и плане выражения языка с помощью тех же понятий «форма» и «субстанция», добавляя к этому все обволакивающую сферу аморфного континуума, или универсума. В труде «Семиотика и философия языка» У. Эко, рассуждая о плане содержания, указывает, что каждая цивилизация организует мыслимое содержание мира по-своему, в виде разнообразных смысловых полей, осей, подсистем, а фрагменты смыслового содержания выделяются в соответствии со специфическим культурным контекстом. Чтобы выразить с помощью языка всё разнообразие понятий, человеку необходимо выбрать другие формализованные порции континуума, соответствующие указанным фрагментам содержания, например звуки языка. Таким образом, материя, или континуум, разделяется на специальные сегменты - слова или другие знаки, чтобы обозначить другие сегменты этого континуума - материальные или воображаемые объекты. Чтобы быть способным к обозначению, естественный язык устанавливает связи между элементами формы выражения и элементами формы содержания, т. е. в языке форма содержания и форма выражения непосредственно взаимодействуют друг с другом, а все субстанции извлекаются человеческой мыслью из аморфнного континуума. Континуум, или универсум, философ схематично представляет в виде сфреры, включающей в себя и план выражения, и план содержания [9]. В более поздней работе У. Эко «Поиски совершенного языка в европейской культуре» форма и субстанция содержания, как и форма и субстанция выражения, схематически представлены уже в виде пластов («strata»), что вновь отсылает к понятиям глоссематики [10, с. 30].

Таким образом мы приходим к выводу, что пространственные представления с неизбежностью применяются философами для описания языка. Поскольку человеческое мышление вообще пространственно организовано, это необходимая составляющая человеческого способа упорядочивать восприятие реальности, действительной или воображаемой.

1. Кант И. Пролегомены / Собр. соч. : в 8 т. М. : Изд-во Чоро, 1994. Т. 4. С. 5-152.

2. Кант И. Критика чистого разума. СПб. : Тайм-аут, 1993. $478 \mathrm{c}$.

3. Кассирер Э. Человеческий мир пространства и времени / Кассирер Э. Избранное. Опыт о человеке. М. : Гардарика, 1998. С. 489-505.

4. Ельмслев Л. Пролегомены к теории языка. М. : КомКнига, 2006. 248 с.

5. Мурат В. П. Глоссематическая теория / Ельмслев Л. Пролегомены к теории языка. М. : КомКнига, 2006. С. 195-244.

6. Deleuze G., Guattari F. A Thousand Plateaus. Capitalism and Schizophrenia. Minneapolis : University of Minnesota Press, 2005. 612 p. 
7. Делёз Ж., Гваттари Ф. Что такое философия? М. : Институт экспериментальной социологии ; СПб. : Алетейя, 1998. $288 \mathrm{c}$

8. Мартишина Н. И. Реальность и ее конструирование. Новосибирск : Изд-во СГУПСа, 2009. 172 с.

УДК 130.2

Науч. спец. 09.00.13

DOI: $10.36809 / 2309-9380-2020-28-55-58$

\section{СФЕРА ПРИВАТНОГО КАК УБЕЖИЩЕ ОТ СТРАХОВ И ТРЕВОГ ВНЕШНЕГО МИРА В ЭПОХУ МОДЕРНА}

В статье исследуется пространство приватности как сфера, защищающая человека от тревог внешнего мира, усилившихся после разрушения традиционной культуры в эпоху Нового времени. Показывается, что процесс индивидуализации принес не только новые возможности, но и необходимость делать личный выбор и нести за него ответственность. Секуляризация породила чувство одиночества и отчужденности в мире без божественного промысла, поэтому в европейской культуре модерна так велика роль уютного домашнего пространства как убежища от внешнего мира. Однако приватное пространство в результате своей закрытости становится еще более опасным, чем публичное.

Ключевые слова: приватность, дом, уют, эпоха модерна, страх, европейская культура.
9. Eco U. Semiotics and the Philosophy of Language. Bloomington : Indiana University Press, 1986. 242 p.

10. Эко У. Поиски совершенного языка в европейской культуре. СПб. : Александрия, 2007. 423 с.

(C) Таскаева Е. Б., 2020

\section{THE SPHERE OF PRIVATE AS A REFUGE FROM THE FEARS AND ANXIETIES OF AN EXTERNAL WORLD IN THE MODERN ERA}

The article examines the space of privacy as a sphere that protects a person from the anxieties of the external world, which intensified after the destruction of traditional culture in the era of modern age. It is shown that the process of individualization has brought not only new opportunities, but also the need to make personal choices and be responsible for them. Secularization gave rise to a feeling of loneliness and alienation in a world without divine providence that is why the role of a cozy home space as a refuge from the outside world is so important in the European culture of modernity. However, private space, as a result of its closed nature, becomes even more dangerous than public space.

Keywords: privacy, home, comfort, modern era, fear, European culture.
Тема приватности в последнее время стала поистине междисциплинарной проблемой, к ней обращаются в психологических, социологических, филологических, философрских исследованиях. Это можно объяснить актуализацией вопросов, связанных с ценностью и достоинством человеческой личности. Наличие приватного пространства дает чувство безопасности, индивидуальной свободы и самоуважения. Право на приватность ослабляет давление государства и общества на человека. К приватному относится то, что закрыто от наблюдения, не является гласным. Это признание права на автономию личной жизни. Ключевые фрормы приватности это физическая, психическая, территориальная и информационная неприкосновенность человека. Понятие приватности, таким образом, соотносится с оппозицией «свой - чужой». Приватными становятся близкие, интимные, неофициальные отношения между людьми. Приватное пространство воспринимается как зона безопасности и свободы.

Сегодня право на неприкосновенность приватной сферы считается само собой разумеющимся, по крайней мере, в западных обществах. Однако разделение публичной и приватной сфер вошло в обиход по историческим меркам совсем недавно: с переходом от традиционного общества к модерну. Развитие индивидуалистической психологии было вызвано изменением экономических, политических и культурных условий.
В традиционной культуре жизненный путь человека был по большей части заранее предопределен и зависел от его сословной принадлежности. Человек был интегрирован в свою общину и занимал принадлежащее ему место в социальной иерархии. Его жизненный мир был стабилен от рождения до смерти. С переходом к индивидуалистическому обществу и капитализму увеличились возможности выбора. Теперь положение индивида в меньшей степени определялось группой, он получал свободу действий, которую мог использовать в своих интересах. Однако теперь человек не просто мог, но был вынужден делать индивидуальный выбор, связанный с его жизнью, и отвечать за него.

Необходимость взять жизнь в собственные руки, после того как были поколеблены такие традиционные социальные институты, как семья или церковь, требовала от субъекта напряжения и усилий. «Индивидуалистическое "Я" имеет дело с миром без посредников, на которых можно бы свалить ответственность. Между мыслящим тростником и бесконечностью нет самодельного, иллюзорного, но... утешительного средостения или укрытия» [1, с. 39]. Индивидуализация предполагала вызовы и напряжения, несла чувство одиночества, оторванности от корней и своей социальной группы, что было платой за новые возможности. Часто эта ноша ответственности оказывалась непосильной, вызывая страх, растерянность и стремление отказаться от своей 